\title{
A DINÂMICA DO MARKETING DE REDE: RELACÕES SOCIAIS E EXPECTAIIVAS DE UM NOVO ESTILO DE VIDA
}

\author{
Antonio José Pedroso Neto \\ Universidade Federal do Tocantins - Brasil
}

Resumo: O foco deste artigo são pessoas que se associaram a uma empresa de marketing de rede. O problema é explicar como se reproduz o corpo de agentes, dado um paradoxo: a empresa Amway do Brasil consegue os agentes - trabalhadores - sem oferecer as garantias e as previsibilidades prescritas em contratos formais e, na extrema maioria dos casos, sem oferecer nem mesmo contrapartida monetária. O objetivo da pesquisa é demonstrar como a Amway se estrutura por meio de um constante processo de instituição de uma nova ordem cognitiva. O modelo analítico considera que o laço social elementar de uma coletividade só é possível quando os indivíduos compartilham em suas mentes um conjunto mínimo de parâmetros sobre a ordem social: convenções sociais instituídas. Na Amway elas são mobilizadas constantemente nas atividades práticas e rituais que visam aumentar e dinamizar as redes, e assim tendem a direcionar a memória coletiva e a se manterem.

Palavras-chave: Amway, antropologia econômica, estilo de vida, marketing de rede.

Abstract: The growth of agents who joined Amway, a network marketing company, presents a paradox: at the same time Amway recruits those agents - as employees -, it don't provide them with legal rights prescribed in formal contracts and, most of the cases, the Company doesn't offer even a monetary return. This research aims to demonstrate how Amway is structured by a continuous process which institutes a new cognitive order. The analytical model considers that the collectivity's elementary social bond is possible only when individuals share in their minds a minimal set of parameters about the social order: instituted social conventions. Inside Amway these instituted social conventions are constantly mobilized through practical and ritual activities which intend to increase and give dynamism to the networks, and thus tend to conduct the collective memory and maintain these social conventions.

Keywords: Amway, economic anthropology, life's style, network marketing. 


\section{Introduç̃o}

Neste trabalho parti de um questionamento comum não só à antropologia e à sociologia econômica: o comportamento utilitarista não é suficiente para explicar o comportamento organizacional dos agentes sociais. Em grande medida, o trabalho começou quando me deparei com uma observação empírica que indicava um paradoxo, dado que o objeto de estudo era uma organização empresarial: uma empresa à qual os agentes se ligavam com o objetivo explícito de obter grandes rendimentos financeiros, como meio para atingir o que chamavam de um "novo estilo de vida" (liberdade financeira, de tempo, renda crescente, realização de sonhos, etc.), reproduzia o seu corpo de agentes sem que a extrema maioria deles recebesse uma remuneração superior à soma dos recursos financeiros investidos na atuação nas atividades da empresa.

O objeto de estudo é uma empresa de marketing de rede - Amway do Brasil - à qual as pessoas se filiavam, tornavam-se distribuidores, para consumir e/ou revender os produtos vendidos pela rede e para patrocinar a filiação de outros distribuidores - formar uma rede de descendentes. Nas duas possibilidades, o distribuidor recebia uma remuneração percentual em relação ao consumo próprio e ao da rede de downliners. Por outro lado, para atuar como distribuidor os agentes se submetiam ao chamado "sistema de treinamento" (ST), isto é, a um conjunto de encontros periódicos, assiduamente frequentados.

Como a filiação à empresa Amway era voluntária e a desvinculação não ficava exposta a nenhum tipo de constrangimento jurídico/formal e poderia ser feita a qualquer momento, inspirei-me nos estudos de Mary Douglas sobre os modelos culturais de organização de grupos sociais. Assim, desde o início, orientei-me pela hipótese de que a estruturação organizacional da empresa é homóloga à de grupos sectários. E, como estratégia de pesquisa, procurei desvendar quais eram as principais estruturas que tornavam o grupo perene e como elas eram produzidas e reproduzidas pelos agentes no momento da ação - as convenções que os agentes produziam e reproduziam na prática quando visam realizar suas pretensões individuais.

Uma característica singular dos grupos sectários é que, dada a ausência de uma hierarquia formal para regular as relações de poder e a distribuição dos recursos, as cisões que dão origem a novos grupos são constantes. Sendo 
assim, as entrevistas deste estudo incidiram sobre dois grupos de agentes: ${ }^{1}$ os de dentro da organização, dentre os quais uns que eram bem-sucedidos, outros que estavam em vias de ascensão e outros que eram recém-filiados; os de fora da organização, que incluíam aqueles que simplesmente deixaram de atuar na empresa e, especialmente, aqueles que saíram da empresa em função de disputas e conflitos (representativos dos momentos e pontos de cisão da rede).

$\mathrm{O}$ confronto dos dados oriundos de entrevistas com agentes em posições discrepantes indicou a necessidade de buscar a objetivação desses conflitos e da lógica de interesses que se desnudava: o consagrado ST revelou-se um empreendimento com fins lucrativos que era mais importante para os grandes distribuidores da Amway do que a própria Amway. Era da venda do material de treinamento que eles obtinham grandes rendimentos.

Procuro explicar como essa lógica era descoberta pelos agentes somente em um determinado momento da sua trajetória na organização, como operava constrangendo e incentivando os agentes e como terminava por produzir certo desencantamento com a atividade. No entanto, ao mesmo tempo, se ela fosse revelada a toda rede de descendentes, representaria uma perda de todo investimento feito pelos agentes até então. Por isso, desde essa descoberta, os agentes passavam a ter um comportamento mais racional, calculista, e seus interesses passavam a girar em torno das possibilidades de reconverter o capital social e simbólico acumulados até então em capital financeiro. Fundamento essas explicações também em dados coletados na esfera da ordem jurídica. Encontrei processos judiciais que objetivavam dados das disputas entre os grandes distribuidores em torno da divisão do lucro gerado pelo ST.

No entanto, não eram somente os interesses econômicos almejados por todos e, de fato, realizados exclusivamente por uma extrema minoria que moviam os agentes. A hipótese principal do trabalho orientava a observar na economia das reciprocidades dos grupos sectários uma cesta mais ampla de

\footnotetext{
O objeto empírico deste estudo é constituído por entrevistas com 16 pessoas, por dados quantitativos e textos publicados na revista da organização (cf. nota de rodapé número 11), por processos judiciais (seis processos tramitados na justiça civil e criminal que envolveram a Amway e a Pronet), por discursos gravados em fitas cassete, por revistas e jornais de circulação ampla, pelo observação participante dos eventos, de textos acadêmicos como livros, dissertações de mestrado e artigos de revistas. O grosso da pesquisa de campo foi realizado entre o primeiro dia do mês de julho e o último dia do mês de outubro de 1999. Dos entrevistados, quatro eram distribuidores ativos. Os 13 restantes eram ex-distribuidores. Entre esses, seis romperam com a Amway em 1997 e, simultaneamente, filiaram-se a uma empresa concorrente.
}

Horizontes Antropológicos, Porto Alegre, ano 16, n. 33, p. 93-120, jan./jun. 2010 
elementos disponíveis para a troca: bens simbólicos, sentimentos, prestígio, noção de pertencimento, aprendizado, família, rede social, capital cultural, capital social, etc. Enfim, parti para a observação de diversos fatores fundados nas relações sociais que incrustam o econômico no social e no cultural.

A partir dessa perspectiva, a pesquisa revelou que os encontros entre os agentes era outro ponto fundamental para explicar a reprodução da coesão organizacional da Amway (os vínculos que permanecem, que têm sobrevida). Tratava-se do que chamo de rituais Amway, quer dizer, das reuniões diárias, semanais, quinzenais, mensais, quadrimestrais, etc. dos agentes locais, regionais, nacionais e internacionais. São reuniões que ocorriam na casa dos agentes e em clubes e hotéis suntuosos. Salvo as reuniões locais que ocorriam na residência dos distribuidores, as demais eram pagas: seja para cobrir os custos de aluguel, equipamento, etc., seja para remunerar os palestrantes que eram os distribuidores do cume da hierarquia de reconhecimento da Amway. ${ }^{2}$ Nesses rituais, os agentes passavam pelo palco para falar de suas experiências de "sucesso", para "ensinar", para "dar o exemplo". Além dessas palestras, geralmente o ápice dos rituais, havia outras atividades de descontração, de apresentação de produtos e, especialmente, o reconhecimento de novos distribuidores em ascensão (atribuição do broche de distinção).

Procuro demonstrar que na Amway os rituais tinham algumas funções constitutivas. Como vimos, eram fontes de rendimentos para alguns distribuidores e o lócus principal onde o grupo reconhecia e consagrava os agentes em ascensão; atribuía o prestígio. Além disso, através deles o grupo realizava o processo de instituição ou estabilização das principais convenções sociais que os agentes compartilhavam. E ainda, era nele que se produzia e difundia um bem coletivo que também contribuía para manter os agentes na rede.

Desse modo, procuro explicar que havia um conjunto de convenções sociais que o grupo veiculava e procurava instituir. Essas convenções eram coerentes, se entrefortaleciam e necessariamente eram mobilizadas performaticamente pelos agentes em momentos cruciais da realização de seus interesses particulares. Basicamente, ao tentar recrutar um novo agente para sua rede, qualquer distribuidor, querendo ou não, acreditando ou não, tinha que

2 Conferir na página 106 a hierarquia de reconhecimento da Amway.

Horizontes Antropológicos, Porto Alegre, ano 16, n. 33, p. 93-120, jan./jun. 2010 
mobilizar o repertório de argumentos e as convenções que ele ouvia o tempo todo no ambiente de sociabilidade criado pelo ST.

Ainda mais particularmente, procuro explicar também que a convenção de que o "sistema de treinamento é educativo e necessário" era reconhecida pelos distribuidores como algo benéfico e útil para cada um deles pessoalmente. Por um lado, eles afirmavam explicitamente que o ST ensinava como "lidar com pessoas", que era um treinamento em formação de lideranças, que ensinava os conhecimentos básicos de relação interpessoal. Por outro lado, essa convenção também tendia a ganhar estabilidade porque o seu conteúdo tinha impacto na vida das pessoas, especialmente as palestras dos grandes distribuidores. As práticas de contato interpessoal aprendidas eram explicitamente referendadas pelos distribuidores com qualidades morais e úteis para a experiência de vida ou para as atividades em outros negócios e profissões. É razoável afirmar que os efeitos do ST, tal como os distribuidores os reconheciam e reproduziam, tornavam-se um bem coletivo produzido pelo grupo.

Em conclusão, procurei apresentar, em resumo, alguns dos diversos fatores sociais que tendiam a soldar o vínculo entre os agentes, independentemente e muitas vezes contra as demonstrações empíricas de que a grande maioria dos distribuidores contribuía com recursos financeiros (e com trabalho e tempo), mas não encontrava reciprocidade justamente nesse ponto que era onde estava seu principal interesse.

\section{0 objeto, o problema e o enfoque}

O foco da análise são as pessoas que se associaram à empresa Amway do Brasil e que pensavam e agiam menos como consumidoras e revendedoras de produtos do que como patrocinadoras: os distribuidores. O distribuidor típico, o agente da Amway, era aquela pessoa que mostrava o plano de marketing da empresa para outras pessoas e participava do ST, enfim, que estava empenhada em montar uma rede.

Os fatos eram os seguintes: a) na década de 1990 a Amway era conhecida e vendia seus produtos no Brasil inteiro. Os produtos tinham a imagem de caros, mas eram vendidos e reconhecidos categoricamente como excelentes, de altíssima qualidade; b) a empresa, durante sua trajetória no Brasil, sempre arregimentou novos distribuidores empenhados. Em outros termos, o trabalho 
dos distribuidores sempre resultou em propaganda da empresa e dos produtos, resultou na venda de produtos, no recrutamento de novos distribuidores e na distribuição localizada de produtos (a casa dos distribuidores era um ponto de distribuição); c) existia outra empresa que funcionava em simbiose com a Amway: a Pronet. Ela promovia os encontros periódicos dos distribuidores, vendia fitas cassete com gravação das palestras dos distribuidores mais qualificados na Amway, vendia livros de literatura de autoajuda, etc. Esse rol de produtos era conhecido e reconhecido como ST. Todo distribuidor necessariamente participava desse ST, quer dizer, consumia seus produtos.

O problema é explicar como se produzia e reproduzia esse corpo de agentes que dinamizavam e expandiam as redes. Todo esse trabalho era exercido por indivíduos que compartilhavam entre si o status e a identidade de empresários independentes. Cada distribuidor Amway identificava a rede de downliners como sua empresa, seu negócio. Para eles, o trabalho de vender produtos, de recrutar consumidores-distribuidores e as práticas adequadas para a performance eficaz das outras atividades definidas e atribuídas pelo grupo aos distribuidores eram atividades empresarias.

O fato para a sociologia é que existia um vínculo de confiança e previsibilidade entre os agentes que, hierarquizados, constituíam a organização. O problema é que esses indivíduos foram socializados e, em sua maioria, vivenciavam relações contratuais no mundo do trabalho em que a prestação de serviços, o trabalho, tinha como contrapartida uma renda, um salário, forçosamente em dinheiro, além de outras garantias sociais. $\mathrm{O}$ fato sociológico é que a Amway conseguia os trabalhadores acima referidos sem oferecer as garantias e as previsibilidades prescritas em contratos formais e, na extrema maioria dos casos, sem conceder contrapartida monetária positiva. A maioria dos distribuidores não recebia uma contrapartida monetária e a maior parte dos que recebiam, não recebia o suficiente para cobrir os gastos com as atividades envolvidas - consumo de produtos da Amway, do ST, viagens, hospedagem, etc.

Mas, de fato, a coesão entre os agentes da Amway era temporária, isto é, a estabilidade dos arranjos de forças que os vinculavam variava numa escala de tempo de zero a nove anos, pelo menos (do início das atividades da empresa no Brasil até o fim do período de coleta de dados desta pesquisa). Não é possível precisar uma média do tempo de vida desses arranjos, mas é razoável afirmar que existem nuvens de pontos numa escala. A pesquisa realizada não permite precisar, mas permite deduzir que existem pontos que aglomeram

Horizontes Antropológicos, Porto Alegre, ano 16, n. 33, p. 93-120, jan./jun. 2010 
conjuntos de vínculos estáveis por três meses, seis meses, um ano, um ano e meio, dois anos, três anos e assim sucessivamente até nove anos. Mas outros fatos importantes são que a organização Amway funcionou, que vínculos permaneceram estáveis independentemente do tempo de vida de cada um e, o mais importante, que esses arranjos básicos de forças de uma estrutura organizacional permaneceram no tempo, ou seja, existiu uma estrutura básica que se manteve independentemente das oscilações no tempo de vida estável dos arranjos. Então, de fato, teve-se coesão, ainda que precária, teve-se uma estrutura permanente, vínculos verticais e assimétricos e agentes oriundos de uma cultura do trabalho remunerado.

Em sua história no Brasil a Amway teve um faturamento relativamente alto e "empregou" milhares de indivíduos. Porém, ela não tinha nenhum vínculo contratual com esses indivíduos que garantisse a previsibilidade da realização, de fato, do trabalho. Não existia nenhum tipo de coerção ou sanção legal, econômica ou material ao indivíduo que se associasse à empresa num dia e saísse quando bem entendesse; trata-se de uma organização em que $o$ vínculo entre os agentes era voluntário. Assim, minha proposta para explicála vai se fundamentar em explicações sociológicas e antropológicas das organizações voluntárias como religiões e seitas.

Minha hipótese é que a estruturação da organização Amway era homóloga à estruturação de organizações voluntárias como as religiosas ou sectárias. Assim, minha perspectiva vai focalizar sobre

la constancia de los habitus socialmente constituidos y reforzados sin cesar por las sanciones individuales o colectivas: en este caso, el orden social descansa fundamentalmente sobre el orden que reina en los cerebros y en los habitus; es decir, el organismo, en cuanto apropiado por el grupo y acorde de antemano con las exigencias del grupo, funciona como materialización de la memoria colectiva, reproduciendo en los sucesores las adquisiciones de los antepasados. (Bourdieu, 1991, p. 95).

Porém, a coesão do grupo não ficava somente à mercê da afinidade e orquestração dos habitus. Essa afinidade, além de ser uma predisposição nos agentes que, por si só, já os tornava vulneráveis à atração exercida pela organização, era orquestrada e reforçada no que estou chamando de rituais Amway. Esses ritos elevavam, ou reanimavam, nos habitus, um conjunto de 
disposições profundamente enraizadas, ou seja, princípios cognitivos mais gerais e profundos, que geravam práticas e crenças - sem passar pela via da consciência ou do cálculo - mais ou menos diversas, mas delimitadas pela existência desses princípios e não de outros. As práticas e as crenças, ainda que temporariamente, estruturavam a organização, ou seja, produziam reciprocamente nos agentes a confiança de que o vínculo entre eles era, de um lado, recíproco e seguro e, de outro, rentável no presente, mas principalmente no futuro.

Nessa perspectiva, os rituais Amway exerciam um trabalho constante de instituição de uma situação particular e distinta como um acontecimento acessível, natural, generalizável, futurístico, enfim, como uma norma universal consagrada e carregada de significados positivos. Assim, meu objetivo é mostrar como a Amway se estruturava através de um constante processo de instituição, inculcação, de uma nova ordem cognitiva sobre uma previamente existente, ou seja, como uma constante produtora e reprodutora da submissão dóxica $^{3}$ de seus agentes aos imperativos da ordem da organização que estava moldando suas estruturas mentais.

\section{0 que é o "negócio Amway"}

Num breve relato sobre a gênese das empresas de marketing de rede, podemos dizer que elas surgiram após a Segunda Guerra Mundial nos EUA na forma das chamadas network Direct Selling Organizations (DSOs) que utilizam as redes de relações sociais dos vendedores. Em 1941, elas estabeleceram um esquema de venda em que os distribuidores poderiam ganhar um bônus de $3 \%$ sobre a venda de pessoas que eles patrocinassem. Em 1959, foi fundada a Amway e em seguida surgiram outras. Em 1950, as network DSOs já tinham os principais traços da sua forma atual: linhas de patrocínio, hierarquia interna de status e caráter emocional e familiar (Biggart, 1989).

As network DSOs oferecem aos vendedores vários meios de compensação que acabam conectando toda a rede. Os meios de compensação econômica são ganhos percentuais - geralmente de $30 \%$ - sobre o valor dos bens

3 Submissão indiscutida, impensada. Uso a palavra "doxa" com o significado de crenças e práticas sociais tidas como normais, evidentes por si mesmas e indiscutíveis (Bourdieu, 1989, p. 13, 43). 
pessoalmente vendidos, os ganhos em forma de bônus por volume de compra, geralmente quando os distribuidores compram por todos os downliners, e os ganhos sobre as vendas de seus downliners e dos downliners recrutados por eles, e assim sucessivamente - esses variam de 3\% a 5\%. Outro meio de compensação são os níveis de reconhecimento interno, ou seja, a hierarquia de status interna à organização - que não correspondem formalmente a níveis de autoridade. Assim, através das duas formas de compensação e das linhas de patrocínio, a independência legal dos vendedores em face da organização é suavizada pela dependência financeira e social.

A variedade dos produtos comercializados pelo conjunto das DSOs não se limita aos cosméticos, que são os principais. Ela se estende a produtos de limpeza, alimentos supercongelados, produtos editoriais, recipientes plásticos de alimentos, suplementos nutricionais, entre outros produzidos pela própria empresa ou por outras empresas.

A Amway é uma DSO atuante no mundo inteiro. Ela tem fábrica própria de alguns produtos, terceiriza a fabricação de outros e vende produtos de outras empresas. Para se ter uma ideia da sua dimensão, em 1990 ela foi a 78 maior companhia privada dos EUA e em 1992, a $30^{\mathrm{a}}{ }^{4}$ Sua expansão internacional começou na década de 1960 e no ano 2000 suas filiais estavam em 49 países, operando em cerca de 80 países e territórios através de doze mil empregados e mais de três milhões de distribuidores cadastrados. Seu faturamento em 1996 foi de US\$ 6,8 bilhões. No entanto, de modo geral, na década de 1990, a dimensão diacrônica da sua equipe e do seu faturamento mundial foi de crescimento e declínio. ${ }^{5}$

A Amway iniciou suas atividades no Brasil em novembro de 1991, e sua história foi de crescimento e queda. O auge foi no ano de 1995, quando a subsidiária brasileira ocupou o quarto lugar dentre as outras espalhadas pelo mundo. No Brasil ela começou faturando US\$ 6 milhões em 1992, atingiu US\$ 150 milhões em 1995 e depois reconheceu a decadência sem apresentar os números. ${ }^{6}$ Os dados sobre o número de associados confirmam a história de

\footnotetext{
4 Fonte: revista Forbes (The 400.., 1991; The 400... 1992).

5 Fonte: Revista Marketing e Negócios (A arma..., 1993); revista Isto é (Camargo, 1994); jornal O Estado de São Paulo (Coelho, 1995); revista Exame (Vassalo, 1997). A imprensa repete os números publicados pela Amway.

6 Conferir as fontes na nota anterior.
} 
crescimento e queda: de 120 mil distribuidores em 1994 ela galgou a $250 \mathrm{mil}$ em 1995 e baixou para 150 mil em 1997.

As DSOs ${ }^{7}$ atuantes no Brasil são visivelmente compostas, em sua maioria, por mulheres. No caso específico da Amway, predominavam as distribuições assinadas por casais - mais de 70\%. Além disso, a Amway se diferenciava das outras DSOs porque levava ao extremo alguns traços característicos das DSOs, de modo geral: vivia em simbiose com um ST pago pelos distribuidores; seus distribuidores realizavam e participavam de encontros "rituais" com frequência semanal, mensal e quadrimestral.

\section{A dimensão utilitarista}

A Pronet era uma empresa que promovia os eventos e vendia o material de treinamento para os distribuidores da Amway, quer dizer, se encarregava do ST. O fato é que a realização dos eventos e a circulação do material de treinamento eram atividades coexistentes com a Amway, e para os agentes o consumo dos mesmos era análogo ao consumo de produtos da Amway. No entanto, tratava-se de empresas distintas que realizam atividades distintas e eram de proprietários distintos. Enfim, do ponto de vista jurídico, uma não podia ser responsabilizada pelas atividades da outra. A comercialização dos produtos do ST, na prática, era realizada prioritariamente pela Pronet, mas existiam também algumas empresas menores intermediárias entre ela e os agentes. Todas essas empresas eram propriedades de distribuidores diamond brasileiros e/ou americanos, agentes do cume da hierarquia de reconhecimento da Amway. ${ }^{8}$

A Pronet do Brasil foi constituída em abril de 1992. Seus sócios eram dois distribuidores diamond norte-americanos e um distribuidor brasileiro que posteriormente tornou-se distribuidor diamond. O faturamento da empresa Pronet desde a sua fundação teve um crescimento exponencial. Os dados que comprovam isso são de um processo judicial em que os sócios norte-americanos

\footnotetext{
7 Em 1995 o mercado de vendas diretas no Brasil movimentou perto de US\$ 3 bilhões e ocupava mais de 1 milhão de pessoas. Nesse mesmo ano, o Brasil era o terceiro país no ranking dos que mais faturaram com as vendas diretas, nesta ordem: Japão, EUA, Brasil, Alemanha. Dentre tantas outras empresas de vendas diretas que precederam ou sucederam a Amway no Brasil temos: Daya; Sociedade Comercial Hermes S/A; Orinflame do Brasil Cosméticos Ltda.; P H Comércio e Serviços Ltda.; Mary Kay do Brasil Ltda.; Contém 1g; Essência Brasil; Bom Apetite; Christian Gray; Jafra; Círculo do Livro; Rhodia; etc.

8 Conferir na página 106 a hierarquia de reconhecimento da Amway.
} 
requereram judicialmente a destituição do sócio brasileiro da gerência da empresa, o direito de novos gerentes ocuparem a sede da empresa e ainda a realização de uma auditoria sobre as atividades e as contas da empresa. ${ }^{9}$

Nesse processo consta que a empresa encerrou o exercício do ano de 1993 com lucro de US\$ 2 milhões. Outro sinal da grandeza do faturamento é o ganho de capital que o brasileiro obteve em quase dois anos de sociedade. Seu capital aumentou mais de 860 vezes, considerando-se o que ele recebeu, em dinheiro, pelas suas cotas na sociedade. O brasileiro destituído conseguiu um acordo, quer dizer, uma soma em dinheiro por suas cotas, porque, na argumentação da sua defesa, sugeria que a polícia federal investigasse os procedimentos dos sócios norte-americanos, que, segundo ele, "rasparam" US\$ 4 milhões do saldo bancário da empresa e de suas filiais após sua destituição, ainda no mês de janeiro de 1994.

E ainda, segundo os resultados da auditoria realizada por uma empresa contratada pelos sócios norte-americanos, a Pronet faturou US\$ 912.475 no mês de outubro de 1993. O faturamento mensal médio da Amway, no mesmo ano, foi de US\$ 5.250.000. Ou seja, a Pronet faturou em torno de um quinto do faturamento da Amway.

Ainda no mesmo processo, a empresa Pronet reconhecia que remunerava os agentes da Amway que promoviam as convenções e comercializavam os materiais do ST, e que alguns deles tinham sua própria empresa para realizar essas atividades. A relação entre essas empresas e a Pronet, ou seja, a relação entre os agentes que ascendiam na Amway e a Pronet era complexa. Pensando em termos de um contínuo, é razoável formular a seguinte proposição de um processo típico. Num extremo estava o distribuidor direto que começava a obter ganhos com os materiais do ST que vendia em "sua rede". Gradualmente, conforme aumentava a rede descendente desse distribuidor (quer dizer, mais distribuidores e maior volume de consumo), aumentava sua qualificação na hierarquia de reconhecimento da Amway e aumentava o número de materiais do ST sobre os quais ele ganhava e a porcentagem do ganho.

No outro extremo, estava o distribuidor diamond. Ele tinha uma empresa que administrava o fluxo de materiais da Pronet à rede de descendentes. As relações comerciais com esses distribuidores não eram firmadas em contratos,

9 Conferir as especificações sobre as fontes de dados na nota de rodapé número 1 . 
em regras formais, explícitas e legalizadas. Mas, no processo judicial observado, os resultados da auditoria revelam a veracidade dessas transações, também objetivadas em relatos nas entrevistas. Enfim, a auditoria permitiu objetivar que o ST era um negócio da alçada dos distribuidores do topo da hierarquia de reconhecimento da Amway. Na auditoria havia: relação de débitos de distribuidores com a Pronet; valor das compras realizadas; duplicatas assinadas; relatos de que a Pronet vendia para distribuidores diretos, desde que fossem autorizados por seus superiores distribuidores diamond; notas fiscais emitidas em um mês para 250 pessoas físicas que consumiram mais ou menos $100 \mathrm{mil}$ fitas cassete; etc.

$\mathrm{Na}$ outra ponta do negócio estavam os consumidores da Pronet, quer dizer, a grande maioria dos agentes da Amway. $\mathrm{O}$ gasto de cada agente ativo com todas as atividades da Pronet no ano de 1999 girava em torno de US\$ 65 por mês, ${ }^{10}$ tendo como base o mês de julho; eram quatro convenções a R $\$ 140$ cada, 12 seminários a R $\$ 15$ cada, 52 reuniões chamadas opens a R $\$ 4$ cada, 52 fitas cassete da semana a $\mathrm{R} \$ 5,90$ cada, 12 livros que custavam em torno de $\mathrm{R} \$ 15$ cada, etc. Deve-se considerar que uma distribuição, na maioria das vezes, era assinada por um casal, o que aumentava os gastos com os eventos. Deve-se considerar que em 1997 gastava-se cerca de US\$ 250 por mês com os produtos da Pronet, fora transporte, vestimenta e alimentação, dado que os distribuidores tinham que se deslocar entre diferentes cidades para participar das reuniões.

Enfim, o ST era uma atividade empresarial com fins lucrativos. Essa atividade era realizada por membros com qualificações proeminentes na Amway e as regras de distribuição dos lucros da atividade como um todo eram desconhecidas pela imensa maioria dos distribuidores. Esses desconheciam até mesmo que o ST era uma atividade empresarial. Até esse ponto tem-se uma das explicações para a reprodução da coesão organizacional da Amway. Todo o arranjo de empresas, rendas, produtos, gastos, etc. supradiscorrido é um ponto modal dessa explicação. A maior parte dos rendimentos dos agentes altamente qualificados fluía dessa modalidade de empreendimento. Esses rendimentos estabilizavam minimamente tais agentes em tais posições e impulsionavam a atividade dos mesmos nos eventos, seminários, etc. E, por fim, a possibilidade de ter ou não acesso aos lucros desse fluxo monetário e os gastos com as

${ }^{10}$ Esclareço que no período a taxa de câmbio entre o dólar e o real era de R\$ 1,00 por US\$1,00. 
despesas do ST definiam uma significativa variável que explica o empenho no trabalho, por um lado, e as rupturas nas redes, por outro lado.

Os agentes que ganhavam com o ST constituíam uma parte pequena em relação ao todo, mas estavam próximos e/ou eram do núcleo de produção simbólica, e assim os efeitos de suas palavras e práticas tendiam a ter reação em cadeia, tendiam a se propagar em ondas para os distribuidores das franjas.

O conteúdo das entrevistas, amparado nos dados sobre o período de crescimento e declínio da empresa, demonstra que existia um pacto implícito entre upliner e downliner quanto à necessidade do ST. Os agentes em ascensão começavam a tomar conhecimento da rentabilidade e da distribuição dos lucros do ST à medida que ascendiam na hierarquia de qualificação, à medida que os números da rede descendente aumentavam; consumo de produtos da Amway e do ST. Nesse momento, eles já recebiam bonificação da Amway e comissão do ST. Os entrevistados revelaram que, por um lado, experimentaram certo descontentamento e desencanto com toda a atividade nesse momento, mas que, por outro lado, estavam em uma situação em que não podiam fazer nada, não podiam revelar o descoberto, pois assim se "mataria a rede".

É razoável afirmar que no espaço dos grandes líderes, mais ou menos em torno da qualificação de distribuidor emerald, os vínculos entre os distribuidores da Amway eram regidos predominantemente por uma negociação racional da competição entre eles. O poder de barganha de um líder nessas negociações dependia da dimensão do seu grupo, da dimensão dos outros grupos de seu upliner e do estado da concorrência entre as empresas de network marketing, dentre outros fatores.

\section{As outras dimensões}

A dimensão utilitarista que explica, em parte, o comportamento de alguns agentes da Amway não reflete e não explica a situação da extrema maioria dos distribuidores e nem os fatos sobre o negócio Pronet eram fatos conhecidos por essa maioria. Ao contrário, a grande maioria dos agentes tinha outra representação e relação como o ST. A tabela a seguir apresenta os níveis da hierarquia de qualificação da Amway, bem como o número de qualificações ocorridas desde o início do processo no Brasil (fevereiro de 1992), até setembro de 1999. Nesse período ocorreram cerca de 4450 qualificações. 
Tabela 1. A hierarquia de qualificacão dos distribuidores e o número de qualificados."

\begin{tabular}{lc}
\hline \multicolumn{1}{c}{ Qualificação } & Quantidade \\
\hline Double Diamond & 1 \\
\hline Executive Diamond & 2 \\
\hline Diamond & 13 \\
\hline Founders Emerald & 6 \\
\hline Emerald & 120 \\
\hline Pearl & 167 \\
\hline Founders Direto & 19 \\
\hline Ruby & 58 \\
\hline Direto & 876 \\
\hline Gold & 1204 \\
\hline Silver & 1985 \\
\hline
\end{tabular}

Fonte: Revista Amagram.

Para um distribuidor atingir uma qualificação do alto da hierarquia, ele tinha que ser qualificado nas precedentes. Sendo assim, de fato, somente algo em torno de 1985 distribuidores foram qualificados nos níveis de qualificação da Amway.

Tomei a qualificação silver como referência para a análise das possibilidades de ascensão nos níveis de qualificação e da possibilidade de auferir bonificação. Tendo como referência os anos em que ocorreram mais reconhecimentos de qualificações silver, temos as seguintes relações percentuais entre o número anual destas qualificações e o número de associações declaradas pela empresa: em 1994, 0,36\% dos distribuidores foram reconhecidos como silver; em 1995, foram reconhecidos $0,43 \%$; em 1996, foram reconhecidos 0,15\%; e em 1997 o percentual foi de 0,02\%. Esse percentual era menor nos

${ }^{11}$ A empresa Amway publicava e distribuía bimestralmente a revista Amagram. Contam como fonte de dados 45 das 46 revistas publicadas até o momento em que encerrei o trabalho de coleta de dados para a pesquisa; a "Edição de Lançamento" (ano 1, n. 1, sem data) e as subsequentes edições bimestrais, desde a primeira (ano 1, n. 2, jan./fev. 1992) até a quadragésima sexta (ano 8, n. 47, jun./jul. 1999). A edição do bimestre dezembro de 1992/janeiro de 1993 (ano 2, n. 7) foi publicada, mas não foi pesquisada porque não foi encontrada. E o que seria a edição número 32 simplesmente não existe. Os editores e impressores cometeram um erro na contagem das edições, pois a edição número 31 se refere ao bimestre dezembro de 1996/janeiro de 1997 (ano 6) e a edição número 33 (ano 6) se refere ao bimestre fevereiro/março de 1997. 
anos anteriores e posteriores aos aqui apresentados. E ainda, ele era extremamente menor quando se tratava das qualificações mais acima na hierarquia.

Enfim, esses números demonstram quão pequenas eram, de fato, as possibilidades de ascensão nos níveis de qualificação da organização, e demonstram quão pequena era a parte do conjunto de pessoas envolvidas com a Amway que, de fato, receberam, ainda que brevemente (cerca de um ano), uma remuneração em torno de US\$ 850 por mês, tendo a qualificação silver e o ano de 1995 como referência.

Dentre outras coisas, isso quer dizer que o comportamento utilitarista ainda que presente na empresa não explica a coesão dos agentes. A extrema maioria dos distribuidores estava na situação de despender cerca US\$250 por mês com os produtos Pronet, fora transporte, vestimenta e alimentação e não estava no rol dos que recebiam alguma remuneração que cobrisse esses gastos.

No entanto, o conteúdo do ST tinha impacto na vida das pessoas, especialmente as palestras dos distribuidores diamond nos eventos. Todos os entrevistados se referiram positivamente às práticas e aos conhecimentos de contato interpessoal aprendidos no ST. Eles atribuíram a eles qualidades morais e úteis para a experiência de vida ou para as atividades em outros negócios, profissões e demais esferas da vida. Eles apresentavam/reconstruíam suas teodiceias pessoais tendo tais práticas e conhecimentos como responsáveis pelas inflexões na carreira, no negócio próprio e da carreira para o negócio próprio. Os entrevistados, em grande medida, reconheceram que participar dos encontros, ouvir as fitas e ler livros (de autoajuda) eram "treinamentos abrangentes" para "lidar com pessoas", "falar com pessoas", "ouvir as pessoas", enfim, que "ajudavam e melhoravam o relacionamento interpessoal". No que diz respeito a seus relacionamentos, reconheceram que com todo o "aprendizado" no ST melhoraram os relacionamentos com os familiares, os amigos, os namorados e as novas pessoas que conheceram na Amway. No que se refere a si mesmo, eles reconheceram que com o "conhecimento adquirido cresceram interiormente", tiveram "desenvolvimento pessoal", "desenvolvimento da segurança para falar em público", "desenvolveram a autoestima", "o autocontrole", se tornaram pessoas "mais ativas", "relacionáveis", "positivas", "mais batalhadoras", "com menos medo de tentar as coisas na vida", etc. E em relação ao universo do trabalho, eles relataram que "aprenderam" muitas coisas que aplicavam na vida profissional, seja num empreendimento próprio ou num emprego em alguma organização: "ganharam na convivência 
com pessoas profissionais" porque com isso "aprenderam a tomar atitudes profissionais", "seguras", "desinibidas", "que facilitam o desempenho", "que ampliam a visão em termos de atuação", etc.

A ampliação das redes de relações sociais também era um efeito prático do ST na vida dos agentes. As pessoas conhecidas após o ingresso na Amway são reconhecidas como amigos que continuaram, mesmo após o desligamento. Alguns entrevistados relataram que continuaram participando dos eventos mesmo após se desligarem da Amway, justamente devido às amizades que teceram e aos aprendizados que continuavam obtendo.

Em conclusão, os efeitos do bem coletivo produzido pelo grupo, de modo geral, dinamizavam a performance e o desempenho dos agentes nas atividades típicas que ampliavam a rede de distribuidores da Amway e dinamizavam também as relações dos agentes fora do mundo da Amway, isto é, com a família, com os amigos, com as pessoas em geral, com outros negócios, etc. De uma forma ou de outra, o aprendizado produzido, difundido e compartilhado nos ambientes de sociabilidade em torno das atividades da organização tinha um efeito reconhecido como positivo, e assim atuava como uma força coesiva que atraía uma grande parte dos agentes, prioritariamente a grande maioria que vivenciava momentos de reconhecimento social.

Com esse reconhecimento geral, afirmo que se tem aqui um dos principais componentes do bem coletivo produzido pelo grupo. Esse reconhecimento e a utilização do mesmo, não somente no mundo da Amway, ampliam o mundo do possível e fornecem motivos, disposições e percepções para o dinamismo dos agentes no trabalho de selecionar as mais diferentes fundamentações para reforçar e reproduzir suas convicções, e, desse modo, a crença no negócio Amway.

\section{As redes sociais que amarram}

Procurei explicar acima o duplo efeito do ST e assim algumas variáveis que explicam a coesão nas redes. Mas há ainda outras variáveis que constituem um rol de explicações. Sem o apoio nos vínculos sociais fora da esfera econômica, a empresa não funcionava. Ela simplesmente não aliciava. Era através da mobilização das relações sociais e dos conteúdos culturais presentes nelas que a empresa conseguia os novos membros, necessariamente. 
Na bibliografia sociológica específica sobre redes sociais temos a definição conceitual de ligações fortes e ligações fracas (Granovetter, 1973, 1995), que guarda alguma analogia com os propósitos deste estudo, na medida em que aborda, de forma sociológica, um tema tradicionalmente abordado pela economia - o mercado de trabalho - e demonstra que não é o mercado livre - postulado explicativo dos economistas -, e sim as instituições sociais, no caso as redes sociais, que orientam a criação e a aquisição das profissões de mais alto status e rendimento econômico.

Granovetter (1973), com fundamentos teóricos e factuais, e, em grande medida, semelhantes a Bott (1976), demonstra que o grau de coincidência da rede social de dois indivíduos varia com a força da ligação entre eles. Uma ligação forte é a combinação da soma de tempo, intensidade de emoções, intimidade e serviços recíprocos decorridos entre os indivíduos. Quanto maior é a frequência da interação, maiores são os sentimentos de amizade recíproca e mais semelhantes eles se tornam. Pensando em termos de um eixo contínuo, quanto mais forte é a ligação do indivíduo A com o indivíduo $\mathrm{B}$, maior é o círculo de amigos que eles têm em comum. No sentido contrário, quanto mais ausente for a ligação, menor o círculo de amigos em comum. No meio do eixo estão as ligações fracas e um número médio de amigos compartilhados. Uma ponte "is a line in a network which provides the only path between two points" (Granovetter, 1973, p. 1364, grifo do autor). A ponte potencializa a difusão de informação e influência. Quando duas pessoas têm muitos contatos, uma ponte entre elas significa uma rota para o fluxo de informações e influências. O importante é que pontes são ligações fracas e são os menores caminhos entre dois indivíduos. Esse é o caminho mais provável e eficiente para transmitir informações que se difundiriam ou até mesmo se perderiam por um caminho muito longo, ou seja, se passassem por vários intermediários.

Assim, as ligações fracas são vistas aqui como indispensáveis para as oportunidades dos indivíduos e para a sua integração em comunidades, e as ligações fortes, como criadoras de uma coesão local. A distribuição espacial da rede de distribuidores Amway foi capilar em todo o território nacional. Segundo as entrevistas e o conteúdo das fitas analisadas é razoável pensar que a sua distribuição e coesão seguiam uma lógica que alternava de núcleos de ligações fortes a núcleos de ligações fortes via ligações fracas. Isso significa que um líder "maior" estava fortemente ligado a outros líderes "menores". As redes de cada um desses líderes "menores" eram pontes para o líder 
"maior" alcançar outros líderes "menores" e suas respectivas redes, e assim sucessivamente.

As entrevistas revelaram uma prática comum dos distribuidores. Logo no início das atividades, eles formaram uma rede de downliners e tendiam a trabalhar (estimular, explicar o funcionamento do marketing de rede) mais com as pessoas que estavam sendo iniciadas e/ou convidadas por seus downliners do que saírem convidando diretamente, por exemplo:

Eu convidei pouquíssimas pessoas, né, porque daí... Logo nas primeiras pessoas convidadas a gente já formou a rede. E, a partir daí, eu trabalhava mais assim amigos desses amigos. Eu ajudava essas pessoas, mas não eu particularmente convidar.

Alguns entrevistados demonstraram que essa tendência foi seguida porque os agentes não queriam continuar convidando as pessoas, ou seja, "tinha uma vergonha" de mobilizar relações pessoais para fins econômicos. Outros entrevistados demonstraram que essa tendência era seguida mais em função do aumento da dimensão do grupo, e assim, da necessidade da constante presença deles em várias reuniões em casa de downliners, etc. Tem-se, assim, um conjunto de redes em que a coesão, ainda que temporária, também era influenciada e reforçada pelas ligações fortes pré ou pós-ingresso nas atividades de distribuidor: parentesco, amizade, vizinhança no início e, em seguida, as proximidades com os superiores, conforme as interações se desdobravam nos diferentes locais de sociabilidade.

Tendencialmente, as pessoas possuem ligações fortes em quantidade mais limitada, mas elas são as ideais para a circulação segura de informações confiáveis, inteligíveis e completas. Além disso, elas se inclinam a ligar pessoas mais próximas no espaço social definido prioritariamente pelos eixos do capital econômico e cultural. Por outro lado, as pessoas tendem a ter um número maior de ligações fracas. Essas duas observações são guias e tipificações analíticas para compreender algumas práticas e representações difundidas e realizadas pelos agentes da Amway.

Uma prática fundamental dos agentes era a confecção de listas de nomes. De modo geral, se uma pessoa fosse convidada por um distribuidor para conhecer o "negócio Amway" e demonstrasse o menor interesse, ela era orientada imediatamente a formular uma lista de nomes de pessoas que ela conhecia e que chamaria para conhecer o mesmo. A estratégia seguinte do distribuidor 
era chegar até as pessoas da lista, conversar com elas, demonstrar o plano de marketing de rede da Amway e tentar conectá-las ao ST (levá-las a algum evento ou deixar com elas a "fita da semana").

Enfim, a partir de um determinado momento, o distribuidor tornava-se um especialista na tática de "arrancar uma lista de nomes" das pessoas e "trabalhar sobre as pessoas da lista". Dessa prática, pelo menos dois desdobramentos eram possíveis. O primeiro é que mais um novo distribuidor começava a ser "amarrado" porque já tinha outras pessoas abaixo dele, com as características da ligação forte supracitadas, por exemplo:

Eu nem tava no negócio eu convidei um amigo meu. [...] e minha sogra [sua upliner] explicou pra ele e ele falou: Sérgio, se você fizer eu tô fazendo também. Aí eu me assustei porque eu nem tava fazendo o negócio e já tava começando a ter resultados. [...] Eu disse pra ele: então você espera porque eu vou voltar para São Paulo amanhã, [...] e a Ofélia [a sogra] me convidou pra uma reunião, e eu vou participar dessa reunião, vou ver direito e depois eu te falo. E depois aí eu realmente participei da reunião [em São Paulo]. Eu fui mais algumas vezes e acabei dizendo pra ele: pode entrar que o negócio é bom. Eu não tava nem em São Carlos e ele já tava fazendo parte da minha rede que a minha... A Ofélia, ela acabou fazendo a assinatura dele pra mim, o contrato.

A segunda é que o distribuidor já tinha em mãos outra lista de nomes que poderia levar a outras, e novamente o processo de "amarrar o cara" ou "arrancar uma lista de nomes" poderia seguir. Essa prática era explicitamente empregada como estratégia, por exemplo:

Assim que uma pessoa entrava, ela tava empolgada. Isso aí a gente era orientado, né. A pessoa entrou, ela tá empolgada. Nessa empolgação ela convida quinhentas mil pessoas pro negócio. E você facilmente cadastrava umas quatro, cinco abaixo dela, né. Rapidinho. Então você meio que largava essa pessoa e ia para a de baixo.

As ligações fortes tendem a conter uma pré-garantia do laço de confiança e previsibilidade que passava a ser reforçado e ganhava novas dimensões com o ingresso dos indivíduos de corpo e alma nos ambientes de sociabilidade da rede. As declarações de alguns entrevistados demonstraram que os convidados reconheciam confiança em quem os convidou. Algumas vezes ela estava relacionada ao parentesco e à amizade: "convite de irmão"; "aceitei por ser amigo"; "só fui porque era minha prima"; "era amigo do meu marido". Outras 
vezes ela estava relacionada ao status profissional: "inclusive os pais deles que convidaram a gente para ver também. [...] Militares. Militares. Os pais deles eram. O pai dele, se eu não me engano, é coronel ou brigadeiro; alguma coisa da aeronáutica." Por outro lado os recém-ingressados na rede reproduziam a mesma prática. Quando questionados a relatarem quem, de fato, eles convidaram, as respostas eram tipicamente as seguintes: de início "as pessoas do seu círculo de amizades", "de trabalho", as pessoas mais próximas com que convivem "mais diariamente", "amigos mais próximos", "colegas de trabalho", "da faculdade", "parentes", "vizinhos", "clientes do supermercado", "amigos de infância". Em seguida, alguns espontaneamente declararam que o ST os instruía a "fazer amizade", "buscar amizades", "rever velhos amigos" e, por fim, aplicar a tática de "arrancar uma lista" de qualquer pessoa ("contato frio") que demonstrasse o mínimo de interesse.

Em conclusão, as ligações fortes eram usadas porque tendencialmente ligam pessoas mais próximas no espaço social e porque todos os elementos institucionais que implicitamente carregam como a tradição, a intimidade, a confiança, o respeito, as reciprocidades, etc. funcionavam na Amway como elementos coesivos das redes, ou seja, como forças que atraíam os indivíduos entre si ou constrangiam o distanciamento. As ligações fracas, por sua vez, eram usadas para a expansão da rede mais geral que continha as redes mais localizadas.

\section{Os rituais e as convencões}

Procurarei explicar como, em um determinado ambiente constituído por determinadas condições culturais e materiais, uma determinada forma organizacional, dentre as inúmeras possíveis, conseguiu reproduzir a sua existência engajando os sentimentos e os pensamentos de seus agentes, produzindo, com eles, uma determinada representação e percepção do mundo.

Em minha perspectiva, o ambiente de sociabilidade gerado em torno das atividades da organização tende a delimitar, fixar e dar confiabilidade às percepções dos agentes que são informadas por conceitos, valores, representações, crenças, práticas, etc. consagradas e veiculadas nesse mesmo ambiente. Esse é o efeito social oculto dos rituais. São esses efeitos que estou colocando em destaque como um fator nada utilitário para explicar a reprodução da coesão organizacional. 
Nos ritos em geral - profanos ou sagrados - se constituem as categorias imperativas do pensamento social. Minha perspectiva vai focalizar sobre os rituais Amway como rituais sociais, entendidos como de instituição, cuja função é criar e naturalizar as instituições sociais (Bourdieu, 1996; Durkheim, 1989; Turner, 1974).

A participação no ST explica a instituição e estabilização de algumas convenções que, sob a forma de princípios cognitivos, ora implícitos ora explícitos, mas sempre arranjados, formam um sistema simbólico que orienta a percepção, a classificação, o esquecimento e a lembrança de informações, fatos, acontecimentos e relações. Desse modo realiza-se o processo de autorreprodução dos distribuidores. Por autorreprodução quero dizer que um corpo de distribuidores, mutável em sua dimensão e constituição, e que algumas convenções e algumas práticas de difusão dessas convenções pelas redes sociais são fenômenos constantes, recorrentes. Isto é, muitos indivíduos passaram pela Amway, mas estes fenômenos permaneceram.

Inspirado em Douglas (1998), traço um modelo analítico que é razoável para ajudar a explicar a reprodução da coesão organizacional da rede de distribuidores da Amway. Na perspectiva dessa autora, o laço social elementar de uma coletividade só é possível quando os indivíduos compartilham em suas mentes um conjunto mínimo de parâmetros sobre a ordem social. E ainda, a fonte de legitimidade das formas mais elementares da sociedade não é o equilíbrio de interesses individuais e, sim, "uma fórmula que encontra sua correção na razão e na natureza" (Douglas, 1998, p. 55). A autora demonstra, de um lado, o processo cognitivo que fundamenta a ordem social e, de outro, "que o processo cognitivo mais elementar do indivíduo depende das instituições sociais" (Douglas, 1998, p. 55).

Segundo sua definição, uma instituição, no mínimo, é uma convenção. Douglas (1998, p. 63) propõe e demonstra que uma convenção se torna uma instituição social legítima apoiando-se em uma convenção cognitiva paralela, ou melhor, que o "aparato cognitivo fundamenta as instituições na natureza e na razão, ao descobrir que a estrutura formal das instituições corresponde a estruturas formais em domínios não-humanos". Ela usa a expressão instituição

no sentido de um agrupamento social legitimado. [...] uma família, um jogo ou uma cerimônia. A autoridade legitimadora pode ser pessoal, tal como um pai, um médico, um juiz, um árbitro ou um maître d'hôtel. Ou então pode ser 
difusa, baseada na concordância comum em torno de algum princípio fundante. (Douglas, 1998, p. 56).

Esse conceito de instituição, por um lado, exclui "qualquer arranjo prático puramente instrumental ou provisional, reconhecido enquanto tal" (Douglas, 1998, p 56). E, por outro lado, inclui a ideia de que as "instituições mais estabelecidas, quando desafiadas, sejam capazes de concatenar suas reivindicações à legitimidade com sua adequação à natureza do universo" (Douglas, 1998, p. 56).

Douglas acha compatíveis com a análise durkheimiana as ideias segundo as quais as instituições são dispositivos que minimizam a quantidade de desordem de um sistema, que começam estabelecendo regras e normas, e podem terminar acumulando todas as informações úteis. Enfim, elas são formas resolver os problemas decorrentes do limite inerente à racionalidade humana. Porém, a autora ressalva que tudo isso não diz como elas começam e se estabilizam para realizar tais tarefas; a estabilidade não pode ser pressuposta, ela tem que ser demonstrada. Douglas propõe que, antes de realizar todo esse trabalho, a instituição precisa de algum princípio estabilizador, uma convenção cognitiva paralela que evite seu desaparecimento ou morte prematura.

Tal princípio estabilizador é a naturalização das classificações sociais. É necessário existir uma analogia por meio da qual a estrutura social de um conjunto fundamental de relações sociais será encontrada ou no mundo físico ou no mundo sobrenatural ou na eternidade ou em qualquer outro lugar, contanto que não seja encarada como um arranjo socialmente elaborado. Quando a analogia é aplicada de um determinado conjunto de relações sociais a outro e vice-versa, e destes conjuntos à natureza, sua estrutura formal recorrente torna-se facilmente reconhecida e revestida de uma verdade que se autolegitima. (Douglas, 1998, p. 58).

O conteúdo das atividades do ST demonstra que ele estava o tempo todo criando, instituindo ou, no mínimo, estabilizando convenções sociais que eram coerentes e simultaneamente se entrefortaleciam. Essas convenções se tornaram os princípios básicos de percepção, de visão e de divisão do mundo. Eles orientavam a seleção, a confiabilidade e a fixação de informações. E eles estavam presentes no discurso performativo dos distribuidores, dos menos aos mais qualificados. Assim, de um lado, esses princípios eram geradores de práticas, representações e discursos performativos que reforçavam as práticas, 
representações e discursos performativos análogos dos outros distribuidores. E, por outro lado, esses princípios se enrijeciam ao gerarem espontaneamente, no "calor" dos conflitos ou das disputas práticas, representações e discursos performativos refratários aos ataques e constrangimentos de outros grupos sociais, os nãos que os distribuidores recebiam, as gozações e até mesmo os insultos.

O principal desafio dos agentes produtores do simbólico, os grandes líderes que já tinham alcançado um "estilo de vida diferente", era estabilizar as principais convenções compartilhadas pelos distribuidores da Amway. Todo o processo de instituição/consagração ocorria principalmente nos rituais Amway e eram reforçados por outras práticas do ST. A seguir procuro demonstrar quais eram as principais convenções criadas ou apropriadas pelos distribuidores, quais eram as convenções paralelas que as estabilizavam e como os distribuidores, indivíduos racionais, agentes sociais, ganhavam impulso para realizar essa tarefa, ou eram constrangidos a realizá-la.

O sistema de treinamento paralelo à Amway é educativo e necessário. Os distribuidores reconheciam que a Amway e a Pronet eram empresas diferentes; aquela vendia os produtos e oferecia a "oportunidade de negócio", e esta ensinava o distribuidor a desenvolver essa oportunidade. Em coerência com essa diferença, eles compartilhavam a ideia básica de que os distribuidores mais experientes, que começaram há mais tempo e já eram bem-sucedidos, eram os que tinham o conhecimento de como "o negócio" funcionava. Repetia-se exaustivamente nas entrevistas e nos rituais a argumentação de que a Amway era um "negócio diferente" e que todo profissional podia ser bom na sua área específica - médico, dentista, empresário, etc. - , mas nas atividades da Amway eles não podiam ensinar nada, ao contrário, tinham que começar do zero. Enfim, por isso a conexão ao sistema era convencionada como fundamental. Reiterava-se demasiadamente uma relação causal entre os "conhecimentos de relação interpessoal" transmitidos pelo ST e a ascensão às qualificações do topo da hierarquia - treinamento é igual a ascensão.

O network marketing da Amway é uma atividade empresarial, um negócio próprio. Os distribuidores estabeleciam uma fronteira entre as atividades da Amway e as atividades das outras empresas de vendas diretas. As primeiras eram tidas como voltadas ao consumo pessoal e familiar e as segundas eram classificadas como voltas às vendas: consumidores em rede versus vendedores em rede. $\mathrm{O}$ objetivo prioritário dos distribuidores era arregimentar 
outros distribuidores e ajudá-los a fazerem o mesmo, e assim sucessivamente para formar uma rede que é um negócio próprio. Os distribuidores também diferenciavam o "negócio Amway" dos "negócios tradicionais" (comerciais, produtivos, de serviços, etc.). Eles traçavam como pontos fronteiriços as benesses espirituais, simbólicas e materiais julgadas possíveis com a atividade na Amway, o "novo estilo de vida" - liberdade financeira, de tempo, renda crescente, realização de sonhos, etc. - em oposição aos problemas que o empreendedor de um negócio tradicional tinha que enfrentar com o mundo do trabalho, com o Estado e com o mercado de modo geral - burocracia, impostos, greve, rigidez das relações, horários e perspectivas econômicas sombrias.

O novo. A noção do novo estava presente na vida diacrônica da empresa no Brasil, com diferentes usos sincrônicos. Do conjunto dos dados, foi possível registrar três núcleos discursivos típicos: um reiterava a recente instalação da Amway no Brasil; outro, mais orientado para os convidados das regiões interioranas dos Estados, enfatizava que a empresa estava começando a se alastrar pelo interior; e outro sublinhava que o network marketing voltado às vendas era uma atividade nova, e que o network marketing voltado ao consumo, isto é, a atividade tida como específica da Amway, era uma atividade "novíssima". E ainda, eles reforçavam o último discurso da novidade com os desdobramentos possíveis em torno do lançamento do site de vendas e patrocínio da Amway - setembro de 1999. O desfecho do discurso profetizava uma revolução, um momento de oportunidades, de geração de novas fortunas, enfim, o relançamento da empresa.

O princípio de duplicação. O plano de marketing da Amway, mais especificamente seu suposto potencial de progressão geométrica, ${ }^{12}$ era consagrado principalmente pela reiteração de que existe um princípio de duplicação: tudo que um upliner faz, os downliners fazem, copiam, isto é, eles imitam desde o consumo de produtos até a participação no ST, passando pela vestimenta, postura corporal, trabalho intenso no início do "negócio", técnicas utilizadas

12 Se um distribuidor A convida três pessoas para participarem do negócio e elas aceitam, sua rede terá mais três distribuidores, B, C e D. Se cada um desses fizer o mesmo, sua rede terá doze distribuidores, e assim sucessivamente. Se os distribuidores aprendem as práticas e os ensinamentos do negócio com seus líderes que já têm sucesso, ocorrerá o mesmo com eles. 
para mostrar o "plano de network marketing" e para lidar com as pessoas, etc. Logo, como não dar certo?

"Network marketing" é uma tendência. De forma geral, a argumentação recorria à construção de uma história da evolução do network marketing que tinha seus pontos modais firmados em algumas convenções coerentes que se entrerreforçavam: a) o homem naturalmente e necessariamente é um consumidor de produtos básicos e de uso contínuo, e a atividade na Amway é uma proposta para o distribuidor tornar-se um consumidor e mudar os hábitos de consumo, isto é, "trocar de supermercado" e entrar no rateio do lucro do novo supermercado; b) a propaganda boca a boca é uma prática humana "natural", "milenar" que o network marketing recompensa, isto é, ele remunera o ato de consumir produtos e indicar quando ele é bom; c) a desintermediação é a grande tendência "socioeconômica", "atual', "mundial" e "futura" porque elimina os gastos com propaganda e intermediários e, assim, proporcionaria o declínio dos preços. O network marketing era apresentado como a forma de desintermediação mais antiga e promissora. As argumentações em torno dessas convenções são amarradas em narrativas performáticas que, de forma geral, tinham o seguinte roteiro e desfecho. Com o network marketing, o produto sai da fábrica e vai direto ao consumidor. $\mathrm{O}$ consumidor ganha poder de barganha por conta da propaganda boca a boca. Há diminuição de custos com a propaganda e com a cadeia produtor, atacadista, varejista e consumidor. Com a diminuição dos custos é possível a participação do próprio consumidor na movimentação financeira do consumo próprio e do consumo dos associados a partir da sua indicação. Essa participação (bônus) é possível na atualidade porque as evoluções da informática ("os computadores da Amway") possibilitaram o cálculo da renda residual gerada nos mais profundos níveis de uma rede. E assim o network marketing voltado à venda tornou-se algo do passado e surgiu a possibilidade do presente o network marketing voltado à associação em rede para o consumo (consumidores associados a consumidores).

A diferença positiva dos produtos. Tratava-se de firmar a distinção dos produtos em sua individualidade ("não se encontra similares no mercado"), no fato de serem importados ("são produtos importados") e, principalmente, na imponente relação vantajosa de custo/benefício do consumo, especialmente porque os produtos-ícones eram concentrados.

O princípio meritocrático. Segundo esse princípio, no "negócio Amway" qualquer pessoa "começa do zero" e as chances de alcançar os resultados

Horizontes Antropológicos, Porto Alegre, ano 16, n. 33, p. 93-120, jan./jun. 2010 
pretendidos são iguais para todos. Quer dizer, o sucesso não depende de escolaridade, idade, cor da pele, religião, profissão, renda e outros atributos sociais, mas tão somente do trabalho e do esforço individual e em equipe.

Enfim, um dos principais efeitos do ST era transformar os agentes investidos, e assim transformar o mundo físico e social através da ação desses agentes (Bourdieu, 1996). Os rituais tendem a instituir no repertório cognitivo dos agentes parâmetros mínimos dentro dos quais as concatenações de suas práticas e representações tendem a reproduzir e estabilizar os mesmos parâmetros. As convenções apresentadas, e outras mais, eram mobilizadas constantemente nas atividades práticas que visavam aumentar e dinamizar os grupos, por exemplo: ao mostrar o plano e as possibilidades do "negócio Amway", o distribuidor mobilizava as convenções apresentadas para ratificar suas afirmações e realizar suas pretensões; ao fomentar o consumo, idem; ao incentivar a participação no ST, idem; e assim, sucessivamente.

Em conclusão, o direcionamento da memória coletiva (Douglas, 1998; Halbwachs, 1990) por essas convenções explica, em parte, como a ordem social se mantém diante e apesar dos questionamentos. De um lado, essas convenções e seus desdobramentos eram lembrados, isto é, faziam parte da memória coletiva, porque eram pontos modais de ratificação e afirmação das pretensões individuais puxadas pela "possibilidade" de ascensão e de se atingir um "novo estilo de vida". De outro lado, a memória coletiva garante a reprodução da ordem social preservando alguns padrões de acontecimentos coletivos como os eventos (e suas benesses monetárias para os líderes e espirituais e simbólicas para grande maioria), a demonstração do plano, o consumo, o patrocínio (imprescindíveis para a realização das pretensões individuais). Dessa forma, é razoável afirmar que os princípios organizacionais tendem a serem aprendidos, apreendidos e reproduzidos por uma espécie de "orquestração sem orquestrador".

\section{Conclusão}

De modo geral, procurei explicar que a organização Amway como um todo, isto é, a simbiose Amway/Pronet funcionava numa lógica organizacional sectária. A partir da mobilização das relações sociais utilizadas para recrutar possíveis distribuidores dava-se uma trama. Poucas pessoas acabavam se envolvendo nessa trama, quer dizer, elas saíam rapidamente do círculo da 
empresa. No entanto, uma parte permanecia, ainda que também por pouco tempo. Mas foi justamente a sobrevida constante dos vínculos que procurei explicar e foram os princípios culturais e as práticas que eram perenes que procurei explicitar, além da trama de concentração de recurso.

Penso que este trabalho, quer dizer, as estruturas que procurei revelar, permite abrir a possibilidade de se estabelecer novos questionamentos em três direções, pelo menos. Temos o tema da exploração e/ou autoexploração dos vendedores e representantes comerciais. O universo das empresas de marketing de rede cresce sistematicamente no Brasil e a lógica de funcionamento de cada uma delas tem maior ou menor semelhança como a lógica de funcionamento que procurei descrever neste artigo. O tema da reconversão de habitus no espaço das classes médias brasileiras também é outro a ser explorado. Em maior ou menor medida, a possibilidade de inserção social via o marketing de rede e/ou a consultoria no âmbito do marketing de rede (e em outras atividades técnicas e econômicas) é uma atividade em expansão na sociedade brasileira desde os anos 1990, pelo menos. E, por fim, pode-se abordar o tema da lógica do capital simbólico como fundamento da confiança em organizações financeiras de curta duração, convencionalmente chamadas de pirâmides. O capital simbólico no âmbito da Amway é produzido internamente nos rituais que consagram os distribuidores e tem existência na medida em que os distribuidores reconhecerem que os grandes distribuidores (diamond especialmente), os grandes líderes, vivem um novo estilo de vida constantemente exibido e emulado em vídeos, imagens e em matérias da revista da organização.

\section{Referências}

A ARMA mais poderosa da década. Revista Marketing e Negócios, ano 1, n. 12 , p. 18-21, jun. 1992 .

BIGGART, N. W. Charismatic capitalism: direct selling organizations in America. Chicago: University of Chicago Press, 1989.

BOTT, E. Família e rede social. Rio de Janeiro: Francisco Alves, 1976.

BOURDIEU, P. O poder simbólico. Lisboa: Difel, 1989. 
BOURDIEU, P. El sentido práctico. Madrid: Taurus Humanidades, 1991.

BOURDIEU, P. Economia das trocas lingüisticas. São Paulo: EDUSP, 1996.

CAMARGO, C. Religião Amway. Isto é, São Paulo, n. 1277, p. 66-67, 23 mar. 1994.

COELHO, E. Amway cresce 19\% e fatura US\$ 6,3 bilhões. O Estado de São Paulo, São Paulo, p. B8, 9 out. 1995.

DOUGLAS, M. Como as instituições pensam. São Paulo: EDUSP, 1998.

DURKHEIM, E. As formas elementares de vida religiosa. São Paulo: Paulinas, 1989.

GRANOVETTER, M. The strength of weak ties. American Journal of Sociology, v. 78, n. 6, p. 1360-1380, 1973.

GRANOVETTER, M. Getting a job. Chicago: The University of Chicago Press, 1995.

HALBWACHS, M. A memória coletiva. São Paulo: Vértice, 1990.

THE 400 largest private companies in the U.S. Forbes, New York, p. 255, 9 dez. 1991.

THE 400 largest private companies in the U.S. Forbes, New York, p. 178, 7 dez. 1992.

TURNER, V. W. O processo ritual: estrutura e antiestrutura. Petrópolis: Vozes, 1974.

VASSALLO, C. Missionários do mundo dos negócios. Exame, São Paulo, p. 52-54, 18 jun. 1997. 